\title{
UJI BALOK BETON BERTULANG MEMADAT SENDIRI HIGH VOLUME FLY ASH 60\% TANPA DAN DENGAN SENGKANG
}

\author{
${ }^{1)}$ Agus Setiya Budi, ${ }^{2}$ Sunarmasto, ${ }^{3)}$ Muhammad Tsaqif Muhadzib, \\ 1),2)Dosen Program Studi Teknik Sipil Fakultas Teknik Universitas Sebelas Maret Surakarta \\ 3) Mahasiswa Program Studi Teknik Sipil Universitas Sebelas Maret Surakarta \\ Fakultas Teknik Jurusan Teknik Sipil Universitas Sebelas Maret Surakarta, \\ Jln Ir. Sutami 36A, Surakarta 57126 \\ Email : muhtsaqif20@gmail.com
}

\begin{abstract}
Self-Compacting Concrete (SCC) is an innovation in construction with many advantages, but behind its advantages SCC requires more cement, so it becomes un-environmental. Fly ash can be used for substances cement with the same characteristic. Fly ash is coal combustion waste containing silica or silica alumina with pozzolan characteristic. The amount of fly ash, which can be used for concrete up to 50\% from whole cement known as High Volume Fly Ash Concrete (HVFAC). This research will examine shear capacity of HV FA-SCC 60\% and normal concrete. The dimension of specimen is $10 \mathrm{~cm} \times 18.5 \mathrm{~cm} \times 130 \mathrm{~cm}$ with 2 points loading with a distance between loads are $20 \mathrm{~cm}$. Based on shear capacity test, $H V F A$ SCC with $60 \%$ fly ash content is smaller than normal concrete.
\end{abstract}

Keywords : Fly ash, hvfa-scc, shear capacity.

\begin{abstract}
Abstrak
Self Compacting Concrete (SCC) merupakan inovasi dalam bidang konstruksi dengan berbagai macam kelebihan, namun terdapat kekurangan yaitu SCC memerlukan proporsi semen yang lebih banyak sehingga tidak ramah lingkungan. Material yang dapat menggantikan semen dengan karakteristik yang sama yaitu fly ash. Fly ash berupa sisa pembakaran batu bara yang mengandung silika atau silika alumina dan bersifat pozzolan. Penggunaan fly ash sebagai campuran beton dapat digunakan hingga mencapai $>50 \%$ dari total semen yang dibutuhkan dan dinamakan High Volume Fly Ash Conccrete (HVFAC). Penelitian ini mengkaji kapasitas geser balok bertulang HVFA-SCC 60\% dan balok beton normal. Benda uji yang digunakan dalam penelitian ini memiliki dimensi $10 \mathrm{~cm}$ × 18,5 cm x $130 \mathrm{~cm}$ dengan 2 titik pembebanan dengan jarak antar beban sebesar $20 \mathrm{~cm}$. Hasil penelitian menunjukkan bahwa kapasitas geser balok yang diuji pada umur 28 hari untuk balok HVFA-SCC 60\% lebih kecil dibandingkan balok beton normal.
\end{abstract}

Kata Kunci : Fly ash, hvfa-scc, kapasitas geser.

\section{PENDAHULUAN}

Pertumbuhan infrasturktur dalam era modern menuntut terciptanya suatu teknologi atau gagasan yang lebih maju untuk meningkatkan efisiensi baik dari waktu maupun biaya. Beton merupakan material yang kerap digunakan dalam konstruksi suatu bangunan dengan bahan pengikat berupa semen. Semen menghasilkan gas buang berupa $\mathrm{CO}_{2}$ yang merupakan salah satu pemicu terjadinya Global Warming. Industri semen menyumbangkan emisi global gas $\mathrm{CO}_{2}$ sebesar $8 \%$. Dengan adanya hal tersebut maka diperlukan suatu penanganan untuk mengurangi emisi gas $\mathrm{CO}_{2}$ yang dihasilkan oleh semen.

Penggunaan semen dapat dikurangi dengan menggunakan fly ash yang memiliki sifat yang mirip dengan semen. Fly ash berupa partikel halus yang memiliki diameter 1-150 mikronmeter serta berbentuk bulat, fly ash merupakan hasil produk sisa umumnya dari pembangkit listrik tenaga batubara. ( Solikin, 2012). Berdasarkan ACI 226, fly ash memiliki butiran relatif halus dimana lolos saringan No. 325 (45 milimikron) 5-27\% dengan berat jenis antara 2,15-2,6 dan memiliki warna abu-abu kehitaman. Kandungan silika $\left(\mathrm{SiO}_{2}\right)$ sangat tinggi dan menghasilkan reaksi pozzolanic. Pozzolan merupakan merupakan bahan yang mengandung silika atau silika alumina yang kemudian beraksi dengan $\mathrm{Ca}(\mathrm{OH})_{2}$ pada suhu biasa yang membentuk senyawa bersifat cementitious (sebagai binder). Beton yang dihasilkan dari campuran fly ash dengan kadar setidaknya 50\% dikenal dengan High Volume Fly Ash (HVFA) Concrete.

Beton pada umumnya memiliki sifat kuat menahan gaya tekan dan lemah terhadap gaya tarik, untuk mengatasi hal tersebut diperlukan baja tulangan yang memiliki sifat kuat menahan gaya tarik. Pada konstruksi bangunan tinggi dan kompleks memerlukan inovasi baru khususnya untuk pekerjaan beton. Salah satu metode yang dapat dipilih adalah menggunakan beton memadat sendiri atau SCC. Beton ini memiliki karakteristik yang dapat mengalir melewati rongga antar tulangan dan memadat dengan sendirinya dengan sedikit bantuan vibrator atau bahkan tidak sama sekali. Self-Compacting Concrete (SCC) menggunakan persentase ukuran agregat dan campuran pasta yang berbeda dengan beton konvensional. Self-Compacting Concrete (SCC) memiliki sifat yang lebih cair dibandingkan dengan 
beton konvensional, sehingga perlu ditambahkan zat kimia berupa superplasticizer disamping untuk meningkatkan workability beton, juga berguna menjaga beton agar tidak terjadi segregasi dan bleeding.

\section{METODE}

Pada penelitian ini digunakan metode eksperimental, yaitu dengan cara melakukan percobaan terhadap benda uji sehingga didapatkan data atau hasil yang diselidiki dalam kondisi terkontrol. Sebelum dilakukan pengujian pada balok, terlebih dahulu dilakukan pengujian terhadap beton segar baik untuk HVFA-SCC maupun beton normal. Pengujian beton segar HVFA-SCC sesuai standar EFNARC meliputi uji flow table, L-box dan $V$-funnel.

\section{Uji flow table}

Uji flow table dilakukan dengan memasukkan beton kedalam kerucut Abrams kemudian dihitung waktu yang dibutuhkan untuk mencapai $\mathrm{T}_{50}$ kemudian mengukur diameter beton dari dua sisi.

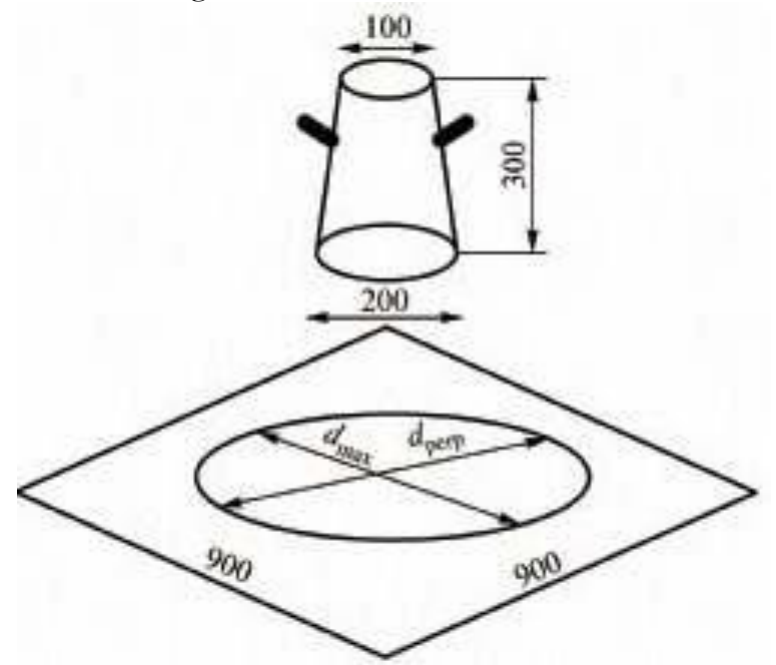

Gambar 1. Kerucut abrams dan baseplate

\section{Uji $L$-box}

Uji L-box dilaksanakan dengan memasukkan beton segar kedalam wadah berbentuk L kemudian melepas pintu penutup agar beton mengalir dan menghitung nilai blocking ratio (h2/h1).

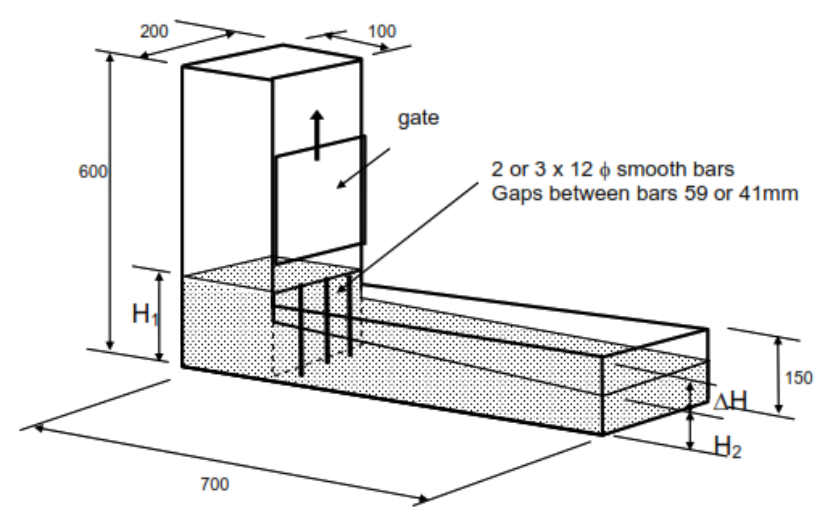

Gambar 2. L-box

\section{Uji $V$-funnel}

Uji $V$-funnel dilakukan dengan memasukkan beton segar kedalam wadah berbentuk V kemudian membuka penutup dan mencatat waktu untuk beton mengalir melewati mulut $\mathrm{V}$-funnel. 


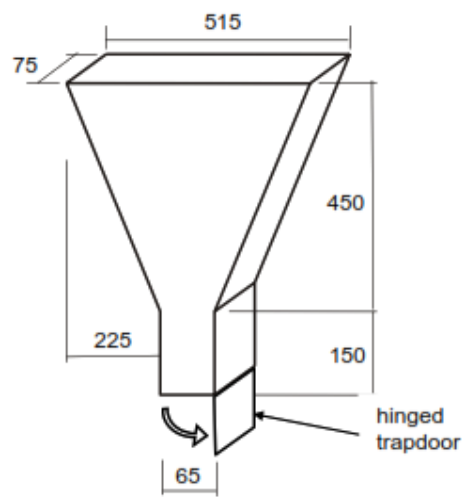

Gambar 3. V-funnel

Pengujian beton segar untuk beton normal dilakukan dengan uji slump dimana beton segar dimasukkan kedalam kerucut Abrams kemudian mengukur ketinggian beton. Penelitian ini dilakukan sesuai dengan urutan kegiatan yang sistematis dan dapat dipertanggungjawabkan.

Sampel yang digunakan berupa balok beton bertulang HVFA-SCC dengan kadar 60\% dan beton normal dengan masing-masing balok berukuran $10 \mathrm{~cm}$ x 18,5 cm x $130 \mathrm{~cm}$ pada umur 28 hari. Model benda uji dapat dilihat pada Gambar 4 sebagai berikut :
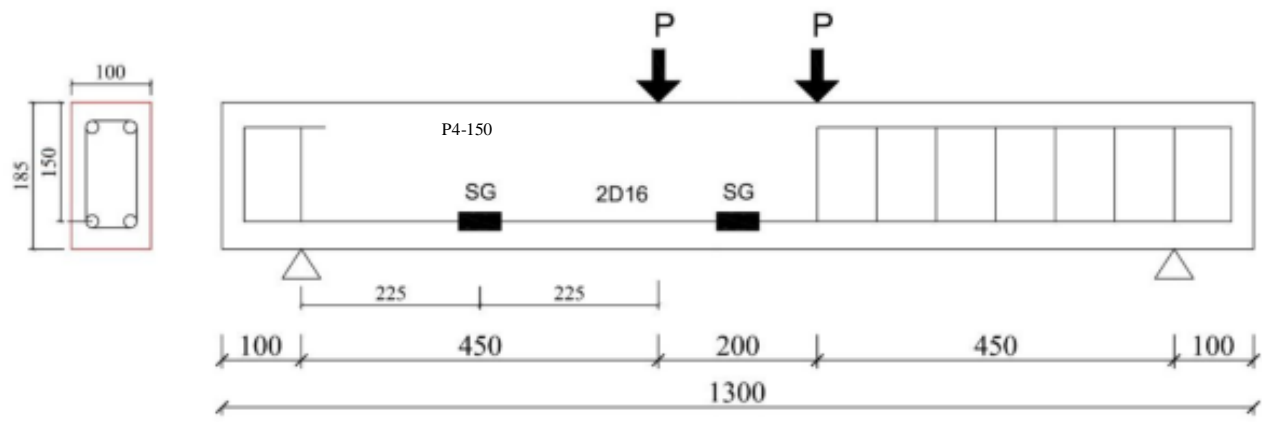

Keterangan :

$\mathrm{P}=$ Beban $\mathrm{SG}=$ Strain Gange

Gambar 4. Model benda uji

Setting up alat pengujian dapat dilihat pada Gambar 2 berikut :

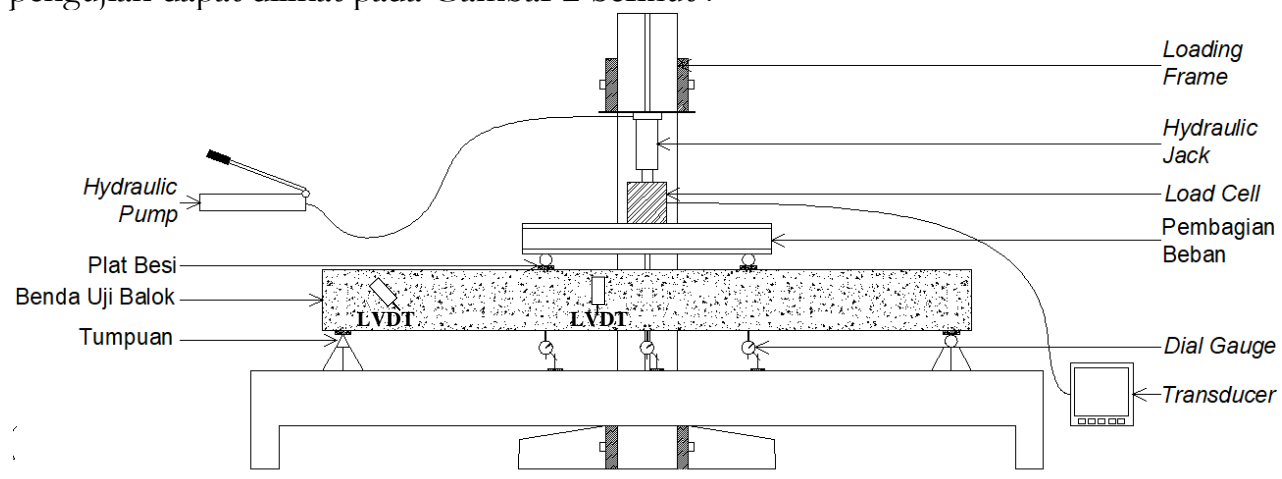

Keterangan :

LVDT = Linear Variable

Differential Transformer

\section{Self Compacting Concrete (SCC)}

Gambar 5. Setting up alat pengujian balok

SCC adalah beton yang memiliki karakteristik dapat memadat secara mandiri sehingga tidak memerlukan vibrator. SCC dapat mengalir mengisi rongga pada tulangan dengan memanfaatkan berat sendirinya. Secara umum SCC adalah beton yang tingkat workability tinggi dan beton segar memiliki kekuatan yang tinggi di awal, dan juga pada saat pembuatan faktor air semen yang dibutuhkan tergolong rendah. Menurut (Sugiharto et al., 2001 ) dan (Sugiharto et al., 2006), hal-hal yang perlu menjadi perhatian untuk menghasilkan beton dengan kekuatan awal yang tinggi adalah sebagai berikut:

1. Jumlah agregat kasar dalam volume beton dibatasi penggunaannya kurang lebih $50 \%$.

2. Jumlah agregat halus dalam volume mortar dibatasi penggunaannya kurang lebih $40 \%$. 
3. Faktor air semen dapat dibatasi penggunaannya dengan menambahkan superplasticizer untuk mendapatkan workability yang tinggi dan kekuatan awal yang besar.

4. Untuk meningkatkan durabilitas dan kekuatan tekan beton dapat ditambahkan filler sebagai bahan pengganti sebagian jumlah semen, contohnya seperti Fly Ash dan Silica Fume.

\section{High Volume Fly Ash (HVFA)}

HVFA merupakan beton yang memiliki ciri-ciri antara lain penggunaan kadar fly ash minimal $50 \%$, water content yang rendah rendah $(130 \mathrm{~kg} / \mathrm{m})$, jumlah semen kurang dari $200 \mathrm{~kg} / \mathrm{m}^{3}$, serta faktor air semen yang rendah $(<0,4)$ (Reiner \& Rens, 2006). Beton HVFA memiliki kandungan air yang rendah dibandingkan dengan beton konvensional sehingga diperlukan superplasticizer untuk meningkatkan workability beton. Beton HVFA memiliki karakteristik berupa kekuatan tekan dan tarik yang dapat menyamai bahkan lebih tinggi dibandingkan dengan beton konvensional (Kumar, Tike, \& Nanda, 2007).

\section{High Volume Fly Ash - Self Compacting Concrete (HVFA-SCC)}

HVFA-SCC adalah beton yang memanfaatkan fly ash sebagai pengganti semen dengan kadar fly ash minimal 50\% dikombinasikan dengan Self Compacting Concrete (SCC) sehingga menghasilkan beton yang kuat serta mempunyai flowablity dan durabilitas yang tinggi.

\section{Kapasitas Geser Balok}

Kuat geser yang terjadi pada balok pada umumnya disertai dengan munculnya desakan dan tarik yang disebabkan oleh lendutan. Geser yang terjadi pada balok dipengaruhi oleh torsi dan kombinasi torsi dengan lentur. (Wang et al., 2007). Sampel uji dalam penelitian ini hanya menggunakan tulangan utama yang bertujuan untuk memastikan balok pada saat pengujian mengalami gagal geser, oleh karena itu kekuatan geser nominal pada balok $\left(\mathrm{V}_{\mathrm{n}}\right)$ hanya dipengaruhi oleh kekuatan geser beton $\left(\mathrm{V}_{c}\right)$.

$$
\begin{aligned}
& V_{u} \leq \phi V_{n} \\
& V_{n}=V_{s}+V_{c}
\end{aligned}
$$

Karena $\mathrm{V}_{\mathrm{s}}=0$, sehingga

$V_{n}=V_{c}$

Menurut ACI Code 318-14, Vc dapat dihitung menggunakan persamaan:

$$
V_{c}-\left(0,16 \sqrt{f^{\prime} c}+17 \rho_{w} \frac{V_{u} d}{M_{u}}\right) b_{w} d
$$

Keterangan :

$\mathrm{V}_{\mathrm{u}} \quad=$ kuat geser ultimit

$\mathrm{V}_{\mathrm{n}} \quad=$ kuat geser nominal

$\mathrm{V}_{\mathrm{s}} \quad=$ kuat geser tulangan sengkang

$\mathrm{V}_{\mathrm{c}} \quad=$ kuat geser beton

$\mathrm{f}_{\mathrm{c}} \quad=$ kuat tekan beton

$\mathrm{P}_{\mathrm{w}} \quad=$ rasio tulangan longitudinal

$\mathrm{b}_{\mathrm{w}} \quad=$ lebar balok

$\mathrm{d} \quad=$ tinggi efektif balok

\section{HASIL DAN PEMBAHASAN}

\section{Hasil Pengujian Bahan}

Uji agregat halus yang dilakukan antara lain pengujian absorbtion, berat jenis semu (apparent specific gravity), berat jenis kering (bulk specific gravity), dan berat jenis kering permukaan jenuh (bulk specific SSD), kandungan zat organik, kandungan lumpur. Hasil uji pada agregat halus ditampilkan dalam Tabel 1.

Tabel 1. Hasil uji agregat halus

\begin{tabular}{llll}
\hline Jenis Pengujian & Hasil Pengujian & Standar & Keterangan \\
\hline Absorpsi & $3,09 \%$ & - & Memenuhi syarat \\
Berat Jenis Semu & $2,59 \mathrm{gr} / \mathrm{cm}^{3}$ & - & Memenuhi syarat \\
Berat Jenis Kering & $2,40 \mathrm{gr} / \mathrm{cm}^{3}$ & - & Memenuhi syarat \\
Berat Jenis Kering Permukaan & $2,48 \mathrm{gr} / \mathrm{cm}^{3}$ & $2,4-2,6 \mathrm{gr} / \mathrm{cm}^{3}$ & Memenuhi syarat \\
Jenuh & & &
\end{tabular}


Jurnal Matriks Teknik Sipil

DOI: https://doi.org/10.20961/mateksi.v8i3

ISSN: $2354-8630$

E-ISSN: 2723-4223

Vol 8, No 4 (2020): Desember

Kandungan Zat Organik

Kandungan Lumpur

Kuning Muda

Kuning Muda

Maksimal 5\%

Memenuhi syarat

Memenuhi syarat

Agregat kasar yang dilakukan meliputi pengujian absorpsi, berat jenis semu (apparent specific gravity), berat jenis kering (bulk specific gravity), berat jenis kering permukaan jenuh (bulk spesific SSD), dan keausan agregat. Hasil uji agregat kasar disajikan dalam Tabel 2.

Table 2. Hasil uji agregat kasar

\begin{tabular}{llll}
\hline Jenis Pengujian & Hasil Pengujian & Standar & Kesimpulan \\
\hline Absorpsi & $0,73 \%$ & - & Memenuhi syarat \\
Berat Jenis Semu & $2,75 \mathrm{gr} / \mathrm{cm}^{3}$ & - & Memenuhi syarat \\
Berat Jenis Kering & $2,70 \mathrm{gr} / \mathrm{cm}^{3}$ & - & Memenuhi syarat \\
Berat Jenis Kering Permukaan Jenuh & $2,70 \mathrm{gr} / \mathrm{cm}^{3}$ & $2,5-2,7 \mathrm{gr} / \mathrm{cm}^{3}$ & Memenuhi syarat \\
Keausan Agregat & $26,92 \%$ & $<50 \%$ & Memenuhi syarat \\
\hline
\end{tabular}

Uji kuat tarik baja sesuai dengan standar ASTM menggunakan mesin Universal Testing Machine dilaksanakan di Laboratorium Material Program Studi Teknik Mesin Fakultas Teknik, Universitas Sebelas Maret Surakarta. Sampel uji baja berupa baja ulir berdiameter $16 \mathrm{~mm}$ untuk tulangan utama dan baja polos berdiameter $8 \mathrm{~cm}$ untuk tulangan sengkang dengan masingi-masing panjang tulangan sebessar $30 \mathrm{~cm}$ dan telah dibubut sepanjang Lo 6,5 cm dengan diameter $13 \mathrm{~mm}$. Hasil pengujian ditampilkan dalam Tabel 3.

Tabel 3. Hasil uji kuat tarik baja

\begin{tabular}{lllllll}
\hline $\begin{array}{l}\text { Benda } \\
\text { Uji }\end{array}$ & $\begin{array}{l}\mathbf{D} \\
\mathbf{( m m})\end{array}$ & $\begin{array}{l}\mathbf{A}_{\mathbf{s}} \\
\left.\mathbf{( m m}^{\mathbf{2}}\right)\end{array}$ & $\mathbf{P}_{\text {leleh }} \mathbf{( N )}$ & $\mathbf{P}_{\text {maks }} \mathbf{( N )}$ & $\mathbf{F}_{\mathbf{y}} \mathbf{( M P a )}$ & $\begin{array}{l}\mathbf{F}_{\mathbf{u}} \\
\mathbf{( M P a})\end{array}$ \\
\hline A & 16 & 158,37 & 72 & & & 620 \\
B & 8 & 49,02 & 21,34 & 28,19 & 435 & 575 \\
\hline
\end{tabular}

\section{Hasil Pengujian Beton Segar}

Uji beton segar HVFA-SCC 60\% berupa Uji V-Funnel, L-Box dan Flow Table. Sedangkan pada beton normal dilakukan uji Slump. Hasil uji tersebut ditampilkan pada Tabel 4,5 dan 6.

Tabel 4. Hasil uji flow table test HVFA-SCC 60\%

\begin{tabular}{|c|c|c|c|c|c|c|c|}
\hline \multirow{3}{*}{ Kode } & \multicolumn{4}{|c|}{ Flow Table Test } & \multicolumn{3}{|c|}{ Syarat menurut } \\
\hline & \multirow[b]{2}{*}{$\begin{array}{l}d_{1} \\
(\mathrm{~mm})\end{array}$} & \multicolumn{2}{|c|}{ Diameter } & \multicolumn{2}{|c|}{ Waktu } & \multicolumn{2}{|c|}{ EFNARC } \\
\hline & & $\begin{array}{l}d_{2} \\
(\mathrm{~mm})\end{array}$ & $\begin{array}{l}d_{\text {rata-rata }} \\
(\mathrm{mm})\end{array}$ & $\begin{array}{l}t_{50} \\
\text { (dt) }\end{array}$ & $\begin{array}{l}\mathrm{T}_{50} \\
\text { (s) }\end{array}$ & $\begin{array}{l}d_{\text {rata-rata }} \\
(\mathrm{mm})\end{array}$ & Keterangan \\
\hline $\begin{array}{l}\text { HVFA } \\
60 \%\end{array}$ & 640 & 680 & 660 & 3 & $2-5$ & $550-850$ & Memenuhi \\
\hline
\end{tabular}

Tabel 5. Hasil pengujian L-Box HVFA-SCC 60\%

\section{L-Box Type}

\begin{tabular}{llllll} 
Kode & $\begin{array}{l}\mathbf{h}_{1} \\
(\mathbf{m m})\end{array}$ & $\begin{array}{l}\mathbf{h}_{\mathbf{2}} \\
\mathbf{( m m})\end{array}$ & $\mathbf{h}_{2} / \mathbf{h}_{\mathbf{1}}$ & $\begin{array}{l}\text { Syarat } \\
\left(\mathbf{h}_{\mathbf{2}} / \mathbf{h}_{\mathbf{1}}\right)\end{array}$ & Keterangan \\
\hline HVFA $60 \%$ & 100 & 90 & 0,9 & $0,8-1,0$ & Memenuhi \\
\hline
\end{tabular}

Tabel 6. Hasil uji V-Funnel HVFA-SCC 60\%

\begin{tabular}{llll}
\hline Kode & T (dt) & Syarat (dt) & Keterangan \\
\hline HVFA $60 \%$ & 6 & $6-12$ & Memenuhi \\
\hline
\end{tabular}

Berdasarkan EFNARC Specification and Guidelines for Self-Compacting Concrete, hasil ini telah memenuhi syarat sebagai beton SCC.

Pengujian slump pada beton normal diperoleh nilai $10 \mathrm{~cm}$. Berdasarkan SNI 7656 2012, syarat nilai slump beton normal adalah 2,5-10 cm. Maka, hasil pengujian memenuhi syarat. 


\section{Hasil Pengujian Kapasitas Geser Balok}

Pada uji balok beton bertulang HVFA-SCC dengan kandungan fly ash 60\% dan balok beton normal didapatkan keruntuhan balok yang dikarenakan adanya gagal geser, yaitu kapasitas geser balok lebih kecil dibandingkan dengan kapasitas lenturnya. Dalam pembahasan ini akan ditampilkan perhitungan mengenai kuat geser dan tegangan geser yang terjadi pada benda uji. Pembacaan lendutan dilakukan setiap interval pembebanan $0,25 \mathrm{kN}$.

Grafik hubungan beban-lendutan hasil uji kapasitas geser kedua sampel uji disajikan pada gambar 6 dan 7 dibawah ini.

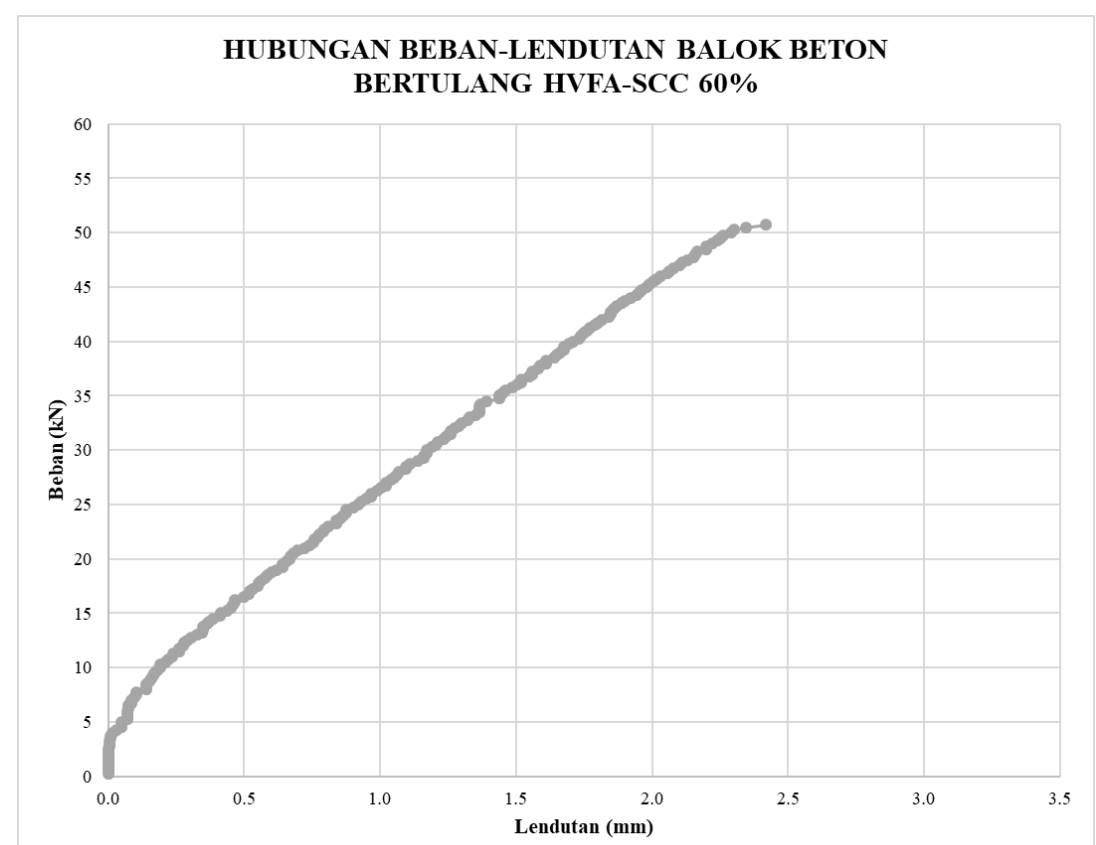

Gambar 6. Hubungan beban-lendutan balok beton bertulang HVFA-SCC 60\%

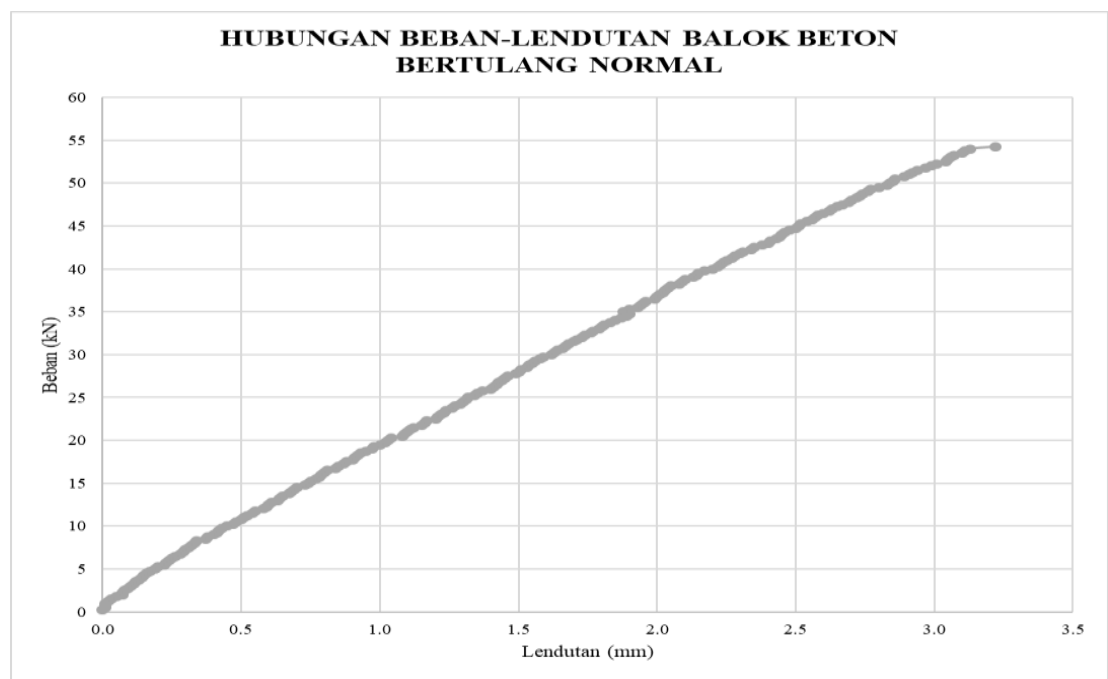

Gambar 7. Hubungan beban-lendutan balok beton bertulang normal

\section{KESIMPULAN}

Berdasarkan grafik hubungan beban-lendutan dapat diketahui bahwa grafik menunjukkan hubungan yang proporsional dimana kenaikan beban selalu diikuti dengan pertambahan lendutan. Balok mencapai lendutan maksimal ketika beban yang diterima mencapai beban maksimal. Apabila beban terus ditambahkan maka balok akan mengalami keruntuhan. Grafik hubungan beban-lendutan tidak menunjukkan adanya degradasi kekakuan disebabkan pada saat terjadinya retak lentur, tulangan lentur belum leleh atau retak-retak yang terjadi masih dapat dikontrol oleh tulangan lentur baik distribusi maupun lebarnya. 


\section{UCAPAN TERIMAKASIH}

Penulis mengucapkan terima kasih yang sebanyak-banyaknya kepada pembimbing yaitu Bapak Agus Setiya Budi, S.T., M.T. dan Bapak Ir. Sunarmasto, M.T. yang telah memberikan ilmu dan arahan dalam proses penyususan ini. Rasa terimakasih penulis ucapkan kepada Tim Beton Cap Orang Tua yang telah berjuang bersama-sama dari awal hingga akhir.

\section{REFERENSI}

Anonim, 1991, “SK SNI T-15-1991-03 : Tata Cara Perhitungan Struktur Beton Untuk Bangunan Gedung”, Bandung.

Anonim, 2005, “The European Guidelines for Self-Compacting Concrete Specification, Production and Use”, The European Federation of Specialist Construction Chemicals and Concrete Systems (EFNARC).

Anonim, 2019, "Building Code Requirements for Structural Concrete (ACI 318-19): An ACI Standard: Commentary on Building Code Requirements for Structural Concrete (ACI 318R-19)", In American Concrete Institute.

Arjun Prasetyo, 2019, "Kapasitas Geser Balok Beton Bertulang High Volume Fly Ash Self Compacting Concrete (HVFA-SCC) dengan Kadar Fly Ash 60\%”, Skripsi, Program Studi Teknik Sipil Universitas Sebelas Maret. Surakarta.

Chu-Kua Wang., Salmon C. G., Pincheira J. A., 2007, “Reinforced Concrete Design 7th Edition”, John Wiley \& Sons, Inc., USA.

Kumar, B., Tike, G. K., \& Nanda, P. K., 2007, "Evaluation of Properties of High-Volume Fly-Ash Concrete”, Journal of Materials in Civil Engineering. Vol. 19 October, pp. 906-911.

Okamura, H. and Ouchi, M, 2003, "Self Compacting Concrete", Journal of Advanced Concrete Technology, Vol 1.

Okamura, H. and Ozawa, K., 1995, "Mix-Design for Self-Compacting Concrete”, Concrete Library of JSCE. Vol. 25, pp. 107-120.

Reiner, M., \& Rens, K., 2006, "High-Volume Fly Ash Concrete: Analysis and Application”, Practice Periodical on Structural Design and Construction, Vol. 11 February, pp. 58-64.

Sugiharto, Handoko, et.al., 2001, "Penggunaan Fly Ash dan Viscocrete pada Self Compacting Concrete", Jurnal Dimensi Teknik Sipil. Vol.8, UK Petra. 